\title{
Barriers and solutions to participation in family- based education interventions
}

\author{
Jamie Lingwood, Rachael Levy, Josie Billington \& Caroline Rowland
}

To cite this article: Jamie Lingwood, Rachael Levy, Josie Billington \& Caroline Rowland (2020) Barriers and solutions to participation in family-based education interventions, International Journal of Social Research Methodology, 23:2, 185-198, DOI: 10.1080/13645579.2019.1645377

To link to this article: https://doi.org/10.1080/13645579.2019.1645377

View supplementary material \lceil

曲 Published online: 25 Jul 2019.

Submit your article to this journal $₫$

Џ Article views: 134

Q View related articles $๘$

View Crossmark data \lceil 


\title{
Barriers and solutions to participation in family-based education interventions
}

\author{
Jamie Lingwood ${ }^{\mathrm{a}}$, Rachael Levy ${ }^{\mathrm{b}}$, Josie Billington ${ }^{\mathrm{c}}$ and Caroline Rowland ${ }^{\mathrm{d}, \mathrm{e}, \mathrm{f}}$
}

aDepartment of Linguistics \& Phonetics, University of Leeds, Leeds, UK; bepartment of Learning and Leadership, Institute of Education, University College London, UK; 'Department of English, University of Liverpool, Liverpool, UK; 'Language Development Department, Max Planck Institute for Psycholinguistics, Nijmegen, Netherlands; 'Donders Institute for Brain, Cognition \& Behaviour, Radboud University, Netherlands; ${ }^{\mathrm{F}} \mathrm{ESRC}$ LuCiD centre, University of Liverpool, Liverpool, UK

\begin{abstract}
The fact that many sub-populations do not take part in research, especially participants from lower socioeconomic (SES) backgrounds, is a serious problem in education research. To increase the participation of such groups we must discover what social, economic and practical factors prevent participation, and how to overcome these barriers. In the current paper, we review the literature on this topic, before describing a case study that demonstrates four potential solutions to four barriers to participation in a shared reading intervention for families from lower SES backgrounds. We discuss the implications of our findings for familybased interventions more generally, and the difficulty of balancing strategies to encourage participation with adhering to the methodological integrity of a research study.
\end{abstract}

\section{ARTICLE HISTORY}

Received 23 November 2018

Accepted 15 July 2019

\section{KEYWORDS}

Shared reading;

interventions;

socioeconomic status (SE);

barriers; families

\section{Barriers to participation}

The lack of diversity in research populations is a growing concern in psychology, health and education. Most research is conducted with Western, educated, industrial, rich, and democratic (WEIRD) participants (Henrich, Heine, \& Norenzayan, 2010), and research on child development and education is no exception. Child development journals are heavily skewed towards research conducted with homogenous populations (Nielsen, Haun, Kärtner, \& Legare, 2017), mostly with white monolingual (often English speaking) middle class people (Barnes, MacPherson, \& Senior, 2006; Ensminger \& Fothergill, 2003; Hogarth, 2005). Participants from lower SES backgrounds, in particular, are consistently underrepresented in research (Manz, Hughes, Barnabas, Bracaliello, Ginsburg-Block, 2010; Nicholson et al., 2011), so much so, that this has been identified as a significant barrier to scientific progress (National Institute of Health, 1994). Research findings from one population may not generalise to another other, which means that advice based on this research may be inaccurate or inappropriate (Mani, Mullainathan, Shafir, \& Zhao, 2013).

A good example of this comes from Odierna and Schmidt's (2009) re-analysis of Lown, Schmidt, and Wiley's (2009) work on levels of violence experienced by low income women with and without children. In the original study, using longitudinal survey data collected from low-income women in a Californian county, Lown et al. concluded that both women without children (who applied for General Assistance; GA) and women with children (who applied for

CONTACT Jamie Lingwood j.lingwood@leeds.ac.uk 0 Department of Linguistics \& Phonetics, School of Languages, Cultures, and Societies, University of Leeds, Leeds, LS2 9JT, UK 
Temporary Assistance to Needy Families; TANF), experienced disproportionately high levels of violence compared to the general population. However, in a re-analysis, Odierna and Schmidt (2009) demonstrated that this conclusion was distorted by non-responsiveness rates. They used a variety of tracking methods to contact 439 of 498 (87\%) original respondents, and reported differences in the results depending on whether or not the sample included or excluded participants who had been difficult to contact (i.e. had required extensive, intensive tracking, including at times, hiring private investigators). Once hard to reach groups were included, rates of violence amongst the GA women were substantially higher than those amongst the TANF women. Findings such as these suggest that failing to reach certain populations limits the external validity and generalisability of many research findings in important ways (Bonevski et al., 2014).

This is a particular problem in educational intervention studies designed to evaluate the effectiveness of an intervention (e.g., a training program designed to teach parents to read more with their children) on a desirable educational outcome (e.g. children's language development). Sign-up rates for intervention studies, especially family-based interventions, in disadvantaged populations are extremely low (Heinrichs, Bertram, Kuschel, \& Hahlweg, 2005), which is likely to distort results since the effectiveness of such interventions varies substantially across different populations. For example, two meta-analyses of shared reading interventions with preschool children reported that effect sizes tend to be smaller in hard-to-reach groups such as children from lower SES backgrounds, children with English as a second language, and children with language disorders (Bus, Van Ijzendoorn, \& Pellegrini, 1995; Mol, Bus, de Jong, \& Smeets, 2008). If this turns out to be the case more broadly, it means that we are substantially over-estimating the effect of such interventions on child outcomes and are drawing flawed conclusions about the costeffectiveness of an intervention for one group (e.g. low SES families) based on evidence from another (e.g. high SES families).

A solution favoured by many is to develop recruitment procedures that target underrepresented groups. However, even then, many researchers fail to meet their targets, either because under-representative groups are less likely to sign up to research, or because they are more likely to drop-out before the end (Justice, Logan, \& Damschroder, 2015; Lengua et al., 1992; Neuhauser et al., 2015). Such groups are traditionally described as 'hard to reach'. The term 'hard to reach' is a ubiquitous term used to broadly define groups of individuals who are eligible to participate in a service, study or intervention, but who, for a variety of reasons, are difficult to involve or access (Brackertz, 2007; Cortis, 2012).

Families may be 'hard to reach' due to a number of powerful social, economic and practical barriers that affect the extent to which they will participate in a research project. There are many suggestions in the literature about how to reach socially disadvantaged populations. Determining what the barriers are, and which solutions are effective at overcoming them, is an important first step in solving our diversity problem in research. In the remainder of this article we first review four barriers to participation from the background literature. Then we describe the solutions we implemented in a case study - a family-based intervention designed to encourage parents to read more with their children - and draw out the implications of our findings for family-based interventions more generally.

\section{Four barriers to research participation facing disadvantaged families}

First, it is difficult to establish contact with families, especially families not already connected to educational support services. Winkworth, McArthur, Layton, Thomson, and Wilson (2010) surveyed 20 disadvantaged single parents who were not well connected to ongoing educational projects and services in their region and showed that these parents lacked the informal networks needed to introduce them to the projects and services. In other words, participants' friends and family were not using the services, and so nor were they. Relatedly, Coe, Gibson, Spencer, and Struttaford (2008) found that families often misunderstood the purpose of 
intervention services, particularly those provided by local authorities; for example, some families thought that Sure Start services could only be accessed by disadvantaged families. This is important because the same research showed that, when these caregivers had been correctly informed about intervention services, many saw the benefits and said that they would use them in the future.

Another way to increase participation in intervention projects is to build rapport with families prior to the start of data collection. To this end, Barley and Bath (2014) advocated the use of a mandatory familiarisation period when working with young children and families, a period which allows researchers and prospective participants to become familiar with one another as well as the setting and staff, before deciding whether or not they wish to participate. Relatedly, many researchers seeking to recruit 'hard to reach' families have used multiple soft-entry points such as open days, taster sessions and coffee mornings in order to give families the opportunity to become familiar with both the location and staff (Koerting et al., 2013). Similarly, both Cortis (2012) and Smith et al. (2014) used buddy scheme initiatives, which encouraged families to bring friends or family members along with them to taster events. The effectiveness of such schemes has not yet been robustly evaluated, but they are a potentially promising method of giving prospective families the confidence to engage in intervention programmes.

A second barrier is that parents may not feel confident in accessing relevant local educational projects and services even when they have been informed about them. Many projects take place in unfamiliar 'third spaces' like libraries/community centres, and there is evidence that some parents lack the confidence to visit unfamiliar spaces (Coe et al., 2008; Smith et al., 2014). Relatedly, many family intervention studies take place in educational settings such as schools, which can have negative associations for parents who did not enjoy or did not complete education. Those families who do not frequently engage with their child's school, or do not feel comfortable in an educational environment, are less likely to engage in interventions that take place in educational settings (Crozier, 1999).

A third type of barrier is 'perceptual' and concerns how the families view the purpose of the research, and the reasons why they have been invited to participate. Families are less likely to participate if they feel they have been specifically targeted because they fit a particular demographic profile (Winkworth et al., 2010), especially if the intervention is focussed on changing parental behaviour in some way. Families are also less likely to participate if they feel that project is intrusive (Heinrichs et al., 2005), especially projects designed to change caregiving behaviours in the private space of the home, or if they think they are being judged or assessed in some way. These perceptual barriers can manifest in different ways. For example, Vanobbergen, Daems, and Van Tilburg (2009) found that parents who took part in a book gift scheme simply ignored the forms of support that they were uncomfortable with; parents who received a 'top 10 reading tips' leaflet as part of an intervention designed to promote 'reading for pleasure' reported that this leaflet made them feel as though they were being assessed on their ability to read. They, thus, chose to ignore it. This last finding is particularly interesting as it implies that advisory materials intended to support parents can operate as barriers themselves if parents feel that the advice implies a negative value judgment (Attride-Stirling, Davis, Farrell, Groark, \& Day, 2004; Barlow, Kirkpatrick, Stewart-Brown, Davis, 2005).

Fourth and finally, some of the more pervasive barriers that families face are of a practical nature. Whittaker and Cowley (2012) reviewed the factors associated with poor attendance at, and engagement with, various types of parenting support programmes, and reported that 'personal life/practical factors' such as lack of time, and working commitments, strongly influenced attendance and engagement with the programmes (see also Hoff, 2003; Snow, Dubber, \& De Blauw, 1982; Waldfogel, 2012). This is especially the case for caregivers with unskilled or semi-skilled jobs (Day, 2013; Harris \& Goodall, 2007), who are less likely to have generous paid vacation schemes, and may be less able to work flexible hours (Heymann \& Earle, 2000). These are strong disincentives to participate and engage in interventions, but simple solutions like scheduling the 
intervention in locations which are accessible for families, and at times convenient for them, can minimise these problems (Smith et al., 2014).

In sum, the literature reviewed above shows that families face a number of powerful social, economic and practical barriers that affect the extent to which they will participate or engage in research. This literature also suggests some potential solutions. However, to date, there are very few studies that take the solutions proposed and implement them in the kind of intervention design that would most benefit from this kind of research. For example, Justice et al. (2015) identified several solutions to caregiver participation in a caregiver-implemented shared reading intervention, but the solutions they proposed were never empirically investigated. Next, we turn to the second aim of the paper, which was to take solutions from the literature and investigate their effectiveness in a family-based shared reading intervention, using a case study approach.

\section{Adopting a case study approach: the reading together project}

The current study is based on data from a randomised controlled trial that was designed to evaluate the effect of a family-based shared reading intervention. In this article, we focus solely on the effectiveness of the procedures we put in place to recruit and retain families with 3-4 year old children, not the effectiveness of the intervention itself, which is currently in preparation. We start by describing the wider context of the importance of shared book reading, then provide details of the case study itself, before evaluating the recruitment and retention procedures.

\section{Context of shared book reading and language development}

Children who enter school with better language skills tend to perform better at school and enjoy better success in adulthood (Blanden, 2006). Conversely, children who enter school with limited language skills are at risk of developing language and associated literacy difficulties later on (Kelley, Goldstein, Spencer, \& Sherman, 2015; Manz et al., 2010). Crucially, preschool children from lower socioeconomic backgrounds are more likely to have poorer language skills on school entry compared with the national average, which means they enter school at a disadvantage, and many never catch up (Qi, Kaiser, Milan, \& Hancock, 2006). Initiatives to promote language development in the early years, especially amongst disadvantaged children, are, thus, at the forefront of many government's social mobility policies (e.g. Department of Education, 2007).

One very effective way to promote language development is via shared book reading, whereby caregivers and children share books together. Shared book reading promotes exactly the kinds of caregiver behaviour that positively impact on children's language development. During shared book reading, adults often use a wider variety of different words, which exposes children to a more diverse vocabulary (Noble, Cameron-Faulkner, \& Lieven, 2018). Books also tend to contain a wider variety of complex sentence structures, many of which are absent in everyday speech to children; and exposure to these benefits older preschoolers' language development (from age 3 years and upwards; see e.g. Rowe, 2012). Book reading is also likely to foster high levels of joint attention because it encourages caregivers and children to focus on the book together, which has been linked to positive language outcomes in younger preschoolers (Farrant \& Zubrick, 2013). Thus, the more we can encourage parents to read with their preschool aged children, especially disadvantaged parents, the more likely these children are to be protected against reading delay and difficulties at school. However, as with interventions more broadly, we find that effect sizes, participation and engagement rates in reading interventions tend to be smaller in in hard-to-reach groups: families from lower SES backgrounds, children with English as a second language, and children with language disorders (Mol et al., 2008; Bus et al., 1995). 


\section{Wider context of the reading together project}

The UK government has made improving language levels in the early years a priority. For example, the department of education's social mobility action plan is to close the word gap in the early years (see Department of Education, 2007 for details). Thus, the government is currently promoting initiatives to create and evaluate interventions for improving children's language development, especially for children from disadvantaged families. The Reader's programme is one such intervention. In this project, called the Reading Together project, we worked in collaboration with a local charity called The Reader, and Liverpool City Council libraries, both of whom frequently run various reading groups within the local community. Forty-three primary caregivers of 3- to 4-year-old children $(\mathrm{M}=3 ; 8, \mathrm{SD}=0 ; 4)$ participated in an eight week-long local Get into Reading programme, ran by The Reader charity that took place in children's preschools. Forty-two further families participated in an active reading control group and were asked to attend their local Story Time reading groups, once a week, which took place in libraries and were run by Liverpool City Council libraries.

The intervention programme had four stages: recruitment (engagement and taster sessions) pre-data collection, delivery of intervention, and post-data collection. Engagement began after an initial meeting with preschool teachers. We arranged to visit each preschool class around 30 minutes before 'pick-up' and 'drop-off' times (i.e. before the morning and afternoon sessions started and again shortly before they had finished). These 'engagement' visits were an opportunity to informally chat with caregivers about the upcoming project, and to distribute leaflets to invite children and their primary caregivers to a book reading 'taster' session which would take place in each of the child's preschools, in the coming days. The 'taster' session was run by the group facilitator from The Reader charity and it focused on shared book reading, nursery rhymes and craft activities. After the 'taster' session, primary caregivers were invited to take part in the research, and a trained researcher enrolled families.

The Reader's programme took place in preschools. For the first 5 weeks, the project worker ran 'Magical Storytimes' which consisted of interactive shared book reading, nursery rhymes and craft activities. During these sessions, project workers read with children using techniques shown to be successful at boosting children's language development. For example, they encourage children to talk about, and around, the book, rather than focus on the text. They also encourage the children and parents to play an active role in the reading session by asking open questions and prompting them to talk about the story. For the final 3 weeks, the project worker supplemented 'Magical Storytimes' 'Stories for You and Yours', in which parents were informed how to read interactively with their child and parents also read aloud with other parents. Story Time reading groups took place in local libraries across Liverpool. These reading groups consisted of interactive shared reading, nursery rhymes, songs and crafts suitable for children under the age of 5, but with considerably less emphasis on interactive responses from the children.

The caregivers and children were all recruited from ten preschools in Liverpool, UK in socioeconomically deprived areas. Preschools in intervention and control groups were matched based on English Indices of Deprivation (IMD), preschool size and Ofsted inspection and regulation ratings. Overall, the intervention and control groups were similar in terms of demographic characteristics (see supplementary material, appendix A). Ethical approval was granted by the University of Liverpool ethics committee. All participating caregivers gave informed consent. At the end of the study, all caregivers were reimbursed with vouchers and books. Preschools were randomised to either the intervention or control condition in accordance with Consolidated Standards of Reporting Trials guidelines (see Schulz, Altman, \& Moher, 2010). For example, all families from five preschools were randomly allocated to take part in The Reader's shared reading programme (intervention group), and the remaining families from five other preschools were randomly allocated to take part in the Story Time groups in local libraries (control group). Reading groups were counterbalanced across two school terms, allowing preschools to take part 
in both the intervention group and the control group. The results of the intervention are reported in a paper that is in preparation.

\section{Barriers to participation in the reading together project, and our solutions}

We identified four potential barriers to participation and put in place four solutions designed to overcome these barriers. We specifically targeted knowledge barriers, confidence barriers, perceptual barriers, and practical barriers (see online supplementary material, appendix B for a summary).

To overcome the knowledge barrier (that families are not aware that the research is happening within the community) we worked through gatekeepers within the community, because positive interest from gatekeepers has been shown to be associated with better access for researchers (Le Compte \& Schensul, 2010). Our gatekeepers were the teachers from the different preschools who participated. We hypothesised that building relationships between researchers and teachers would encourage teachers to take an active interest in the project, which would lead them, in turn, to actively encourage families to participate. In order to investigate the success of this strategy, we recorded sign-up rates across preschools. We are not aware of any literature which specifies the threshold for success here (i.e. what proportion of eligible families signing up would be deemed a success), but given the cost of The Reader's shared reading intervention, we decided our solution would be effective if we managed to recruit $50 \%$ of the eligible families within the preschool classrooms we targeted.

The second barrier is a confidence barrier; that some families do not feel confident in participating in a research project, particularly if it takes place in an unfamiliar environment (Coe et al., 2008; Smith et al., 2014). Our solution was to use the preschool, a familiar space, for both phases of recruitment - engagement and taster sessions. These sessions also gave families the opportunity to become familiar with the project staff (Koerting et al., 2013). To evaluate the success of this strategy, we measured how many families who attended the taster session later signed up, and how many went to the first intervention session. Again, given the cost of The Reader's shared reading intervention, we decided we would deem our solution a success if we managed to engage $50 \%$ of parents to sign up to the project and attend the first session.

The third barrier identified (the perceptual barrier) was that families may feel they are being targeted because they fit a particular demographic profile (Winkworth et al., 2010), or may feel that they were being judged in some way, particularly given that the project was targeted at disadvantaged families, but was run by researchers from a high profile local university. To counteract potentially negative perceptions of the project, we implemented two solutions. First, we used a familiarisation period (consisting of engagement and taster sessions), prior to sign up, as recommended by Barley and Bath (2014). This familiarisation period allowed us to meet parents twice, once within an engagement session designed to explain the aims of the research in a concise and transparent manner, and again within a taster session, which allowed them to experience taking part before signing up. Second, we partnered in the project with trusted local organisations (The Reader and Liverpool City Council libraries). To test whether these solutions addressed the issue of negative perceptions, we measured the extent to which both parents and children enjoyed participating in the project, by asking caregivers to evaluate how much they and their children enjoyed taking part in the project.

The fourth barrier is practical; personal life/practical factors such as lack of time and working commitments can strongly influence attendance and engagement (Smith et al., 2014; Whittaker \& Cowley, 2012). Our solution was to schedule the intervention sessions at a convenient time and location for parents. Sessions took part in the children's preschools, first thing in the morning or afternoon preschool session, straight after drop-off time. Our reasoning was that parents would be more motivated to attend if all they had to do was stay an extra 30-60 minutes after arriving at preschool, rather than make a special journey. Note that our control group sessions were existing Story Time library groups, which ran at various times throughout the day. Thus, it was not 
possible for us to schedule these reading groups at drop-off time. This led us to predict that the intervention sessions would be better attended than the control group Story Time library sessions. We tested this by measuring weekly attendance rates.

\section{Implementing the recruitment and retention strategy}

Initially, twelve preschools were approached and asked if they would be willing to participate in the project. Ten of the twelve agreed to participate and an initial meeting at each of the preschools was set up with a senior teacher and the preschool teacher. This initial meeting was attended by the lead researcher and the project worker from The Reader who would be running the intervention reading groups. This was an opportunity for us to build rapport with the preschool, to describe the aims and objectives of the project, and to answer any questions relating to the project. It was also an opportunity to arrange the logistical details (e.g. dates, times, locations) for recruitment, intervention delivery and data collection with each preschool.

As described earlier, we arranged to visit each preschool class around 30 minutes before pickup and drop-off times for an engagement session. These engagement visits were an opportunity to informally chat with caregivers about the upcoming project, and to distribute leaflets to invite children and their primary caregivers to a taster session which would take place in each of the child's preschools.

In order to investigate the success of our solutions, we made the following observations. To examine whether building relationships with families and schools through engagement and taster events would increase families' awareness of the existence of the Reading Together project, we calculated what proportion of eligible families signed up to the project from participating preschools. To examine whether using familiar spaces and engaging families through a taster session would increase families' confidence in participating in the project, we calculated how many families signed up at the taster event, as well as how many came along to the first reading group. To examine whether associating with a third sector organisation and promoting 'reading for pleasure' through taster sessions would encourage families to feel less judged or targeted, we asked caregivers to evaluate how much they and their children enjoyed taking part in the project, on a scale from 1 (not enjoyable at all) to 5 (very enjoyable). Finally, we examined the success of scheduling the shared reading groups in convenient, familiar and local locations and at a convenient time of day (where possible), by observing weekly attendance rates. The group facilitator recorded the number of dyads present at each reading group.

\section{Findings from the case study}

In the following section, we describe and evaluate the effectiveness of the solutions we identified in the wider context of previous research.

\section{Barrier: Families may not be aware of the existence of the Reading Together project.}

\section{Solution: Build relationships with families and schools through engagement and taster events.}

Our aim was to encourage (i) teachers to take an active interest in the project and thus, themselves, encourage (ii) prospective families to participate in the project. Building relationships with preschools, teachers and families is an important part of 'entering the field' (Berg, 2009) and some researchers have advised that rapport be built during an extended 'familiarisation' period (Barley \& Bath, 2014). With this in mind, we set aside six weeks in which to identify schools and engage families as part of the recruitment process. To investigate the effectiveness of our strategy, we examined how many families signed up to the Reading Together project across both school terms. We then calculated the proportion of sign-ups relative to the preschool class size (see 
online supplementary material, appendix C for further details). Two preschools could not provide us with class size numbers and are therefore not included in our analyses. Overall, 10\% (37 out of 366) of eligible families signed up to participate in the Reading Together project, ranging from $2 \%$ to $20 \%$ (between 1 out of 60 families in one school, and 7 out of 35 families in another school).

This is considerably lower than the $50 \%$ target that we were aiming for. A number of factors may have contributed to this. First, not all families were available on the day of the engagement and taster sessions. It was only possible for us to host a taster event at each school in either the morning or the afternoon session, given our limited research resources. Therefore, any families who were not available for the taster session, because they were in preschool on different days or times to when the taster session was held, would have slipped the 'recruitment net'.

Nevertheless, the number of uptakes varied considerably across preschools, from $2 \%$ to $20 \%$ (between 1 out of 60 families in one school, and 7 out of 35 families in another school). It is not clear why this is but during our initial meetings with teachers, we observed that many gatekeepers (i.e. the preschool teachers who would allow us access to families) were enthusiastic about being part of the project and recognised the importance of the study. Indeed, some preschool teachers were particularly influential in informing caregivers about the Reading Together project and many teachers encouraged families to attend the taster event, including those who were not present at the engagement event. Additionally, when teachers were present in the preschool during the engagement events, this arguably legitimised the project to families, thus encouraging families to participate. Therefore, we suggest that a plausible hypothesis is that we were more successful in recruiting families if the teacher was enthusiastic about it - a view that accords with research showing that positive interest from gatekeepers is associated with improved participant access (Le Compte \& Schensul, 2010). However, this hypothesis will need to be tested in further research; perhaps by rating the enthusiasm of the teachers for the intervention before it begins, and then analysing whether there was a positive relationship between enthusiasm ratings and number of sign-ups.

\section{Barrier: Families may not be confident in participating in the project.}

\section{Solution: Use familiar spaces and engage families through a taster session.}

Holding the engagement sessions at drop-off and pick-up times allowed the researchers and project worker from The Reader to informally talk to families to encourage them to participate in a taster session. Given the evidence that families often lack confidence in using some services (Coe et al., 2008; Smith et al., 2014), particularly those which are located in unfamiliar places, we ensured that the engagement and taster sessions took place in each of the children's preschools.

This strategy was very effective. All $(100 \%, \mathrm{n}=85)$ families who attended the taster sessions opted to sign up to participate in the Reading Together project, which exceeded our sign-up target of $50 \%$. In addition, of the families who signed up to participate in the project, $58 \%(\mathrm{n}=49)$ came to the first reading group, which took place a few days after the taster session. Again, this exceeded our first week attendance target of $50 \%$.

However, collapsing this figure across reading group reveals that significantly more families from the intervention group came along to the first reading group $(M=72 \%, \mathrm{SD}=45 \%, 31$ out of 43$)$ than families from the control group ( $M=43 \%, \mathrm{SD}=50 \%, 18$ out of 42 families) as confirmed by an independent samples t-test $(\mathrm{t}(83)=2.82, p<0.01, \mathrm{~d}=0.61)$. The striking difference in attendance between the intervention and control group may relate to the location itself. Those in the intervention group were returning to familiar locations for their first reading group, whereas those in the control group were going to their local library, which may have been an unfamiliar location for many families. This is in line with previous findings which have found that families may not feel confident in attending a group if it takes place in an unfamiliar environment (Coe et al., 2008; Smith et al., 2014).

It should be noted that although the unfamiliar location of the Story Time' reading groups was a barrier to participation, changing the location of the Story Time reading groups was not feasible in the current study; our pre-registered research question was to evaluate the effectiveness of The 
Reader's shared reading programme by comparing this with existing reading groups within the community. Changing the location of the Story Time reading groups would have jeopardised the integrity of this research. Therefore, there was a clear conflict between managing 'setting-related' barriers and adhering to pre-registered research protocols. This demonstrates the difficulty in balancing methodological needs and strategies to encourage participation.

\section{Barrier: Families may feel judged or targeted}

\section{Solution: Associate with third sector organisations; promote 'reading for pleasure' through taster sessions}

The third barrier related to parents potentially feeling targeted or judged by literacy or book reading initiatives (Vanobbergen et al., 2009). For example, caregivers may have misinterpreted the taster session for a book reading lesson, or they may have felt that the taster session would lead them feel scrutinised about their own reading abilities. To overcome this barrier, we used engagement sessions to explain to caregivers why we were running a taster session and what the project entailed. We presented the taster session as a fun and enjoyable, rather than a teaching or learning, activity. Caregivers may also have felt judged or targeted not because of the initiative itself, but because many initiatives are run by those who work for educational authorities (e.g. schools or universities). We hypothesised that being affiliated with two local organisations, The Reader and Liverpool City Council who frequently work within the local community, would also encourage families to participate.

One of the ways to quantify the extent to which we mitigated any barriers associated with feeling judged or targeted is by observing the extent to which families enjoyed participating in the project. After the reading groups had finished, we asked caregivers to evaluate how much they and their children enjoyed participating in the Reading Together project, on a scale from 1 (strongly did not enjoy taking part) to 5 (strongly enjoyed taking part). Overall, caregivers $(M=4.27$, $\mathrm{SD}=1.01)$ and children $(M=4.24, \mathrm{SD}=0.88)$ both enjoyed participating in the project.

Again when we collapse these mean scores across group, caregivers $(M=4.69, \mathrm{SD}=0.55)$ and children $(M=4.58, \mathrm{SD}=0.58)$ in The Reader's shared reading groups provided significantly more favourable scores than caregivers $(M=3.68, \mathrm{SD}=1.20)$ and children $(M=3.79, \mathrm{SD}=1.03)$ in the Story Time group $(\mathrm{t}(23.50)=-3.40, p<0.01, \mathrm{~d}=1.08 ;(\mathrm{t}(43)=-3.26, p<0.01, \mathrm{~d}=0.95)$ (see appendix $\mathrm{D}$, online supplementary material). This suggests that families may have had different experiences of the project depending on which reading groups they had been allocated to. In line with this, we received some anecdotal feedback from caregivers who reported that they felt that some of the Story Time reading groups were inappropriate for their children's age or oversubscribed. Therefore, whilst there was no indication that families felt judged or targeted in any way, there were other unanticipated content-related issues which may have impeded engagement with the reading groups (Whitaker \& Cowley, 2012). To maintain the integrity of the research, we were unable to make any changes to alleviate these concerns. Once again, there was a conflict between abiding by research guidelines and being able to address participants' feedback on content-related barriers.

\section{Barrier: The timing and location of the reading groups.}

\section{Solution: Schedule the reading groups in convenient, familiar and local locations and at a convenient time of day (where possible).}

Fourth and finally, personal life/practical factors such as lack of time and working commitments can strongly influence attendance and engagement (Whittaker \& Cowley, 2012). Our solution was, where possible, to schedule the reading groups when caregivers would be dropping their children off at preschool, to minimise additional travel, and to situate them in familiar and local locations (Smith 
et al., 2014). However, while we were able to schedule The Reader's shared reading groups at drop off time, it was not possible to schedule the Story Time reading groups at drop off time.

To quantify the extent to which we successfully mitigated practical barriers, we observed the extent to which families participated in the weekly reading groups. On average, families attended fewer than three out of the eight shared reading groups $(M=2.48, \mathrm{SD}=2.90)$. Again, however, when we collapsed these mean scores across group, the findings showed that families who took part in The Reader's shared reading group attended an average of $4.23(\mathrm{SD}=2.94)$ reading groups (53\% attendance) and families in the Story Time group attended an average of 0.69 (SD = 1.35) out of eight groups ( $9 \%$ attendance). This difference in attendance was statistically significant, as confirmed by an independent samples $\mathrm{t}$-test $(\mathrm{t}(59)=-7.16, p<.001, \mathrm{~d}=1.55)$.

It is difficult to pinpoint precisely why the Story Time reading groups were not as well attended as The Reader's shared reading groups. Aside from the familiarity of the location or the timing of the groups, our findings also showed that caregivers and children did not enjoy the Story Time reading as much as The Reader shared reading groups. Furthermore, attendance at the Story Time reading groups dropped considerably after the first week before remaining stable across weeks 2-8 in both groups (see supplementary material, appendix E). This suggests that some families may not have enjoyed the Story Time groups (in particular) enough to return to the groups in subsequent weeks. Indeed, content related barriers discourage engagement in programmes (Attride-Stirling et al., 2004; Barlow et al., 2005; Heinrichs et al., 2005) and it is likely that content, attendance and enjoyment were related.

\section{Unanticipated barriers}

There were additional barriers which we had not anticipated. Whilst we set aside six weeks to identify schools and engage families as part of the recruitment phase, we would have benefitted from having more time for this phase of the project. This became particularly evident during recruitment for cohort 2 in September. September is when new children come to school for the first time, and many preschools stagger new starters, who only attend on a part-time basis for the first few weeks of term. In addition, teachers and families will be less familiar with each other, so we anticipated that families were less likely to respond positively to the teachers attempts to recruit them to the study. To address this issue, we took the decision to delay the initial proposed timeline (i.e. recruitment phase, pre-data collection, delivery of intervention, post-data collection) by two weeks to allow the children more time to settle in to the school. This was the maximum number of weeks we could push the schedule back by, within the school term, to allow sufficient time to collect post-data before the Christmas break. However, by pushing back the schedule, this also meant we had less time to engage families at the engagement and taster events during the recruitment phase. This demonstrates the importance of being able to adopt flexible and adaptable research timelines.

As well as collecting measures on children's language and attitudes to reading, we also invited caregivers who were allocated to the intervention reading groups to participate in an optional interview and video-recording of shared reading at home. A restricted timeframe and limited research staff numbers required us to adopt an all-or-nothing approach whereby caregivers who opted to participate were asked to take part in both an interview and a shared reading session, rather than one of the intended activities. In reality, a number of caregivers declined to participate in these activities because, while they were happy to consent to participate in an interview, many felt uncomfortable with the idea of being filmed. Videoing is an intrusive activity and caregivers may have felt pressurised into providing an authentic 'performance' of reading. Indeed, only 6 out of the 43 eligible families participated in these additional researcher activities. One way to overcome this would be to lengthen the period of data collection and to separate the intended research activities. For example, caregivers may have been interviewed on one day, before deciding whether they also wished to participate in a shared reading session. However, this solution requires additional time and resources, both of which were limited in the current 
study. Nonetheless, we acknowledge that it is important to consider how prioritising timeframes and deadlines can affect recruitment.

\section{Conclusion}

The aim of the current paper was to review the relevant literature on barriers to participating in intervention studies, and then use a case study approach to evaluate the success of four potential solutions implemented in a shared reading intervention for families from lower SES backgrounds. Below we make some recommendations based on our findings.

First, (1) we recommend allocating a substantial amount of time and resources to the familiarisation period. During the familiarisation period, we held both engagement sessions, where researchers meet with eligible families to explain the project, and taster sessions, where parents could experience taking part before they sign up. We also recommend that (2) researchers work to ensure that gatekeepers are not only involved, but that they recognise the value of the project; so that they work together with the researchers to engage families, and encourage them to take part. In addition, we recommend that researchers (3) consider carefully the time of year and the timeframe of the researcher; have gatekeepers had time to build relationships with families before the intervention starts? Do families have enough time to consider the implications of participation before they decide to take part? Can more, and less, intrusive and intensive parts be separated, to maximise recruitment to at least some parts of the intervention?

The solution we implemented here were partially successful. Only $10 \%$ of eligible families across preschools opted to participate in the project, partly because we did not have the resources available to meet in person with every eligible family. However, $100 \%$ of all families who came along to the taster session opted to sign up to participate in the project, and more than half of families attended a reading group in week one. Therefore, although encouraging families to go along to a taster session is a difficult first step, all families who made that important first step subsequently chose to participate in the project.

We also recommend that researchers (4) affiliate with trusted local organisations where possible, and (5) work hard to communicate the goals of the intervention clearly, and to ensure that participants do not feel judged or targeted. It is important that the intervention is seen as an enjoyable and worthwhile experience, as families will not continue to participate in an intervention they do not enjoy. We also recommend that (6) intervention sessions are held at locations, and at times, that are convenient, and familiar, to the families taking part, to encourage both recruitment and retention.

Overall, we were moderately successful here. Families enjoyed participating in the project and attended more than half of the reading groups, on average. Crucially, however, families who participated in The Reader's shared reading groups enjoyed taking part in the project more, and attended the reading groups more often, than families who participated in the Story Time reading groups. The content, location and the timing of the reading groups may have contributed to these group differences.

Finally, however, we recommend that consideration is given to (7) balancing recruitment and retention strategies with the integrity of the research design. While it is important to do what we can to reduce the impact of barriers to participation, it is equally important to make sure that these strategies do not compromise the ethical or methodological integrity of the study. This prevented us addressing some of the barriers to participation that the families experienced.

\section{Acknowledgments}

This research was funded by the Economic and Social Research Council [ES/L008955/1; ES/M003752/1]. The analysis of this data, and initial drafts of the paper were carried out when Jamie Lingwood was at the University of Liverpool, Rachael Levy was at the University of Sheffield, and while Caroline Rowland was funded at the ESRC LuCiD Centre by the Economic and Social Research Council at the University of Liverpool ([ES/L008955/1]). 


\section{Disclosure statement}

No potential conflict of interest was reported by the authors.

\section{Funding}

This work was supported by the Economic and Social Research Council [ES/L008955/1; ES/M003752/1].

\section{Notes on contributors}

Dr. Jamie Lingwood is a Research Fellow in the Department of Linguistics \& Phonetics at the University of Leeds, UK.

Dr. Rachael Levy is an Associate Professor in the Department of Learning and Leadership at the Institute of Education, University College London, UK.

Dr. Josie Billington is a Reader in the Department of English and Deputy Director for the Centre for Research into Reading, Literature and Society at the University of Liverpool, UK.

Prof. Caroline Rowland is the Director of the Language Development Department at the Max Plank Institute for Psycholinguistics, Professor at the Donders Institute at Radboud University, Netherlands, and, Professor at the ESRC International Centre for Language and Communicative Development (LuCiD Centre) at the University of Liverpool, UK.

\section{References}

Attride-Stirling, J., Davis, H., Farrell, L., Groark, C., \& Day, C. (2004). Factors influencing parental engagement in a community child and adolescent mental health service: A qualitative comparison of completers and non-completers. Clinical Child Psychology \& Psychiatry, 9, 347-361.

Barley, R., \& Bath, C. (2014). The importance of familiarisation when doing research with young children. Ethnography and Education, 9, 182-195.

Barlow, J., Kirkpatrick, S., Stewart-Brown, S., \& Davis, H. (2005). Hard-to-reach or out-of-reach? Reasons why women refuse to take part in early interventions. Children \& Society, 19, 199-210.

Barnes, J., MacPherson, K., \& Senior, R. (2006). Factors influencing the acceptance of volunteer home visiting support offered to families with new babies. Child and Family Social Work, 11, 107-117.

Berg, B. (2009). Qualitative research methods for the social sciences. Boston, MA: Pearson Education.

Blanden, J. (2006). "Bucking the trend": What enables those who are disadvantaged in childhood to succeed later in life? London: Department for Work and Pensions. Retrieved from http://dera.ioe.ac.uk/7729/1/WP31.pd.

Bonevski, B, Randelvanl, M, Paul, C, Chapman, K, Twyman, L, Bryant, J, \& Hughes, C. (2014). Reaching the hardto-reach: a systematic review of strategies for improving health and medical research with socially disadvantaged groups. BMC Medical Research Methodology, 14, 1-29.

Brackertz, N. (2007). Who is hard to reach and why? Retrieved from: http://library.bsl.org.au/jspui/bitstream/1/875/ 1/Whois_htr.pdf

Bus, A. G., Van Ijzendoorn, M. H., \& Pellegrini, A. D. (1995). Joint book reading makes for success in learning to read: A meta-analysis on intergenerational transmission of literacy. Review of Educational Research Spring, 65, 1-21.

Coe, C., Gibson, A., Spencer, N., \& Stuttaford, M. (2008). Sure start: Voices of the 'hard-to-reach'. Child: Care, Health and Development, 34, 447-453.

Cortis, N. (2012). Overlooked and under-served? Promoting service use and engagement among 'hard-to-reach' populations. International Journal of Social Welfare, 21, 351-360.

Crozier, G. (1999). Parental involvement: Who wants it? International Studies in Sociology of Education, 9, $219-238$.

Day, S. (2013). “Terms of engagement" not "hard to reach parents". Educational Psychology in Practice, $29,36-53$.

Department of Education (2007). Unlocking talent, fulfilling potential: A plan for improving social mobility through education. Retrieved from: https://assets.publishing.service.gov.uk/government/uploads/system/uploads/attach ment_data/file/667690/Social_Mobility_Action_Plan_-_for_printing.pdf

Ensminger, M. E., \& Fothergill, K. E. (2003). A decade of measuring SES: What it tells us and where to go from here. In M. H. Bornstein \& R. H. Bradley (Eds.), Socioeconomic status, parenting, and child development (pp. 13-27). New Jersey: Lawrence Erlbaum Associates, Inc.

Farrant, B. M., \& Zubrick, S. R. (2013). Parent-child book reading across early childhood and child vocabulary in the early school years: Findings from the longitudinal study of Australian children. First Language, 33, $280-293$. 
Harris, A., \& Goodall, J. (2007). Engaging parents in raising achievement. Do parents know they matter? London: Department for Children, Schools and Families.

Heinrichs, N., Bertram, H., Kuschel, A., \& Hahlweg, K. (2005). Parent recruitment and retention in a universal prevention program for child behavior and emotional problems: Barriers to research and program participation. Prevention Science, 6, 275-286. doi: 10.1007/s11121-005-0006-1

Henrich, J., Heine, S. J., \& Norenzayan, A. (2010). The weirdest people in the world? Behavioral and Brain Sciences, 33, 61-135.

Heymann, S. J., \& Earle, A. (2000). Low-income parents: How do working conditions affect their opportunity to help school-age children at risk? American Educational Research Journal, 37, 833-848.

Hoff, E. (2003). The specificity of environmental influence: Socioeconomic status affects early vocabulary development via maternal speech. Child Development, 74, 1368-1378.

Hogarth, R. M. (2005). The challenge of representative design in psychology and economics. Journal of Economic Methodology, 12, 253-263.

Justice, L. M., Logan, J. R., \& Damschroder, L. (2015). Designing caregiver-implemented shared-reading interventions to overcome implementation barriers. Journal of Speech, Language, and Hearing Research, 58, S1851-S1863.

Kelley, E. S., Goldstein, H., Spencer, T. D., \& Sherman, A. (2015). Effects of automated tier 2 storybook intervention on vocabulary and comprehension learning in preschool children with limited oral language skills. Early Childhood Research Quarterly, 31, 47-61.

Koerting, J., Smith, E., Knowles, M. M., Latter, S., Elsey, H., McCann, D. C., .. Sonuga-Barke, E. J. (2013). Barriers to, and facilitators of, parenting programmes for childhood behaviour problems: A qualitative synthesis of studies of parents' and professionals' perceptions. European Child \& Adolescent Psychiatry, 22, 653-670.

Le Compte, M., \& Schensul, J. (2010). Designing \& conducting ethnographic research: An introduction (Vol. 1). London: Altamira Press.

Lengua, L. J., Roosa, M. W., Schupak-Neuberg, E., Michaels, M. L., Berg, C. N., \& Weschler, L. F. (1992). Using focus groups to guide the development of a parenting program for difficult-to-reach, high-risk families. Family Relations, 41, 163-168.

Lown, E. A., Schmidt, L., \& Wiley, J. (2009). Interpersonal violence among women seeking welfare: Unraveling lives. American Journal of Public Health, 96, 1409-1415.

Mani, A., Mullainathan, S., Shafir, E., \& Zhao, J. (2013). Poverty impedes cognitive function. Science, 341, 976-980.

Manz, P. H., Hughes, C., Barnabas, E., Bracaliello, C., \& Ginsburg-Block, M. (2010). A descriptive review and meta-analysis of family-based emergent literacy interventions: To what extent is the research applicable to low-income, ethnic-minority or linguistically-diverse young children? Early Childhood Research Quarterly, 25, 409-431.

Mol, S. E., Bus, A. G., de Jong, M. T., \& Smeets, D. J. H. (2008). Added value of dialogic parent-Child book readings: A meta-analysis. Early Education and Development, 19(7), 26.

National Institute of Health. (1994). Guidelines on the inclusion of women and minorities as subjects in clinical research. NIH Guide, 23, 2-3.

Neuhauser, A., Ramseier, E., Schaub, S., Burkhardt, C. A., Templer, F., \& Lanfranchi, A. (2015). Hard to reach families - A methodological approach to early recognition, recruitment, and randomization in an intervention study. Mental Health \& Prevention, 3, 79-88.

Nicholson, L. M., Schwirian, P. M., Klein, E. G., Skybo, T., Murray-Johnson, L., Eneli, I., ... Groner, J. A. (2011). Recruitment and retention strategies in longitudinal clinical studies with low-income populations. Contemporary Clinical Trials, 32, 353-362.

Nielsen, M., Haun, D., Kärtner, J., \& Legare, C. H. (2017). The persistent sampling bias in developmental psychology: A call to action. Journal of Experimental Child Psychology, 162, 1-38.

Noble, C. H., Cameron-Faulkner, T., \& Lieven, E. (2018). Keeping it simple: The grammatical properties of shared book reading. Journal of Child Language, 45, 753-766.

Odierna, D. H., \& Schmidt, L. A. (2009). The effects of failing to include hard-to-reach respondents in longitudinal surveys. Research and Practice, 99, 1515-1521.

Qi, C. H., Kaiser, A. P., Milan, S., \& Hancock, T. (2006). Language performance of low-income African American and European American preschool children on the PPVT-III. Language, Speech, and Hearing Services in Schools, 37, 5-16.

Rowe, M. L. (2012). A longitudinal investigation of the role of quantity and quality of child-directed speech in vocabulary development. Child Development, 83, 1762-1774.

Schulz, K. F., Altman, D. G., \& Moher, D. (2010). CONSORT 2010 statement: Updated guidelines for reporting parallel group randomised trials. BMC Medicine, 8, 1.

Smith, E., Koerting, J., Latter, S., Knowles, M. M., McCann, D. C., Thompson, M., \& Sonuga-Barke, E. J. (2014). Overcoming barriers to effective early parenting interventions for attention-deficit hyperactivity disorder (ADHD): Parent and practitioner views. Child: Care, Health and Development, 41, 93-102.

Snow, C. E., Dubber, C., \& De Blauw, A. (1982). Routines in mother-child interaction. In L. Feagans \& D. C. Farran (Eds.), The language of children reared in poverty (pp. 53-72). New York: Academic Press.

Vanobbergen, B., Daems, M., \& Van Tilburg, S. (2009). Bookbabies, their parents and the library: An evaluation of a flemish reading programme in families with young children. Educational Review, 61, 277-287. 
Waldfogel, J. (2012). The role of out-of-school factors in the literacy problem. The Future of Children, 22, 39-54.

Whittaker, K. A., \& Cowley, S. (2012). An effective programme is not enough: A review of factors associated with poor attendance and engagement with parenting support programmes. Children \& Society, 26, 138-149.

Winkworth, G., McArthur, M., Layton, M., Thomson, L., \& Wilson, F. (2010). Opportunities lost - Why some parents of young children are not well-connected to the services systems designed to assist them. Australian Social Work, 63, 431-444. 